\title{
A protocol for quantifying mono- and polysaccharides in seawater and related saline matrices by electro-dialysis (ED) - combined with HPAEC-PAD
}

\author{
Sebastian Zeppenfeld ${ }^{1}$, Manuela van Pinxteren ${ }^{1}$, Anja Engel ${ }^{2}$, and Hartmut Herrmann ${ }^{1}$ \\ ${ }^{1}$ Atmospheric Chemistry Department (ACD), Leibniz-Institute for Tropospheric Research (TROPOS), Leipzig, Germany \\ ${ }^{2}$ GEOMAR Helmholtz Centre for Ocean Research Kiel, Kiel, Germany
}

Correspondence: Hartmut Herrmann (herrmann@tropos.de)

Received: 9 January 2020 - Discussion started: 17 January 2020

Revised: 26 May 2020 - Accepted: 2 June 2020 - Published: 16 July 2020

\begin{abstract}
An optimized method is presented to determine dissolved free (DFCHO) and dissolved combined carbohydrates (DCCHO) in saline matrices, such as oceanic seawater, Arctic ice core samples or brine using a combination of a desalination with electro-dialysis (ED) and highperformance anion exchange chromatography coupled to pulsed amperometric detection (HPAEC-PAD). Free neutral sugars, such as glucose and galactose, were found with $95 \%-98 \%$ recovery rates. Free amino sugars and free uronic acids were strongly depleted during $\mathrm{ED}$ at $\mathrm{pH}=8$, but an adjustment of the $\mathrm{pH}$ could result in higher recoveries $(58 \%-$ $59 \%$ for amino sugars at $\mathrm{pH}=11 ; 45 \%-49 \%$ for uronic acids at $\mathrm{pH}=1.5$ ). The applicability of this method for the analysis of DCCHO was evaluated with standard solutions and seawater samples compared with another established desalination method using membrane dialysis. DFCHO in field samples from different regions on Earth ranged between 11 and $118 \mathrm{nM}$ and DCCHO between 260 and $1410 \mathrm{nM}$. This novel method has the potential to contribute to a better understanding of biogeochemical processes in the oceans and sea-air transfer processes of organic matter into the atmosphere in future studies.
\end{abstract}

\section{Introduction}

The majority of organic matter (OM) in oceanic seawater can be assigned to the chemical classes of proteinogenic amino acids, carbohydrates and lipids (Benner and Kaiser, 2003; Kaiser and Benner, 2009; Kuznetsova and Lee, 2002; Marty et al., 1979; Skoog et al., 1999; Wakeham et al., 1997). Previous studies uncovered that combined amino acids are the most abundant organic substances in fresh particles sinking within the water column (Wakeham et al., 1997), although more recent studies indicate that carbohydrates may be equally abundant (Cisternas-Novoa et al., 2019), while hydrolyzable carbohydrates dominate the chemical composition of dissolved organic matter (DOM) (Kaiser and Benner, 2009; McCarthy et al., 1996). Marine carbohydrates also appear in high concentrations in other related saline matrices, such as ice cores, brine and melt ponds in the Arctic (Ewert and Deming, 2013; Underwood et al., 2013; Zeppenfeld et al., 2019). Hence, a reliable analysis of carbohydrates is essential for understanding biogeochemical processes in the ocean and their impact on Earth's atmosphere.

Most marine carbohydrates exist as polysaccharides or combined carbohydrates (CCHO), which are linear or branched chains of monosaccharides, including hexoses, pentoses, deoxy sugars, amino sugars and uronic acids. In aquatic environments, $\mathrm{CCHO}$ either appear in a particulate (PCCHO) or dissolved form (DCCHO). In living marine microorganisms including prokaryotes, polysaccharides assume their functions as structural compounds or as energy storage (Skoog and Benner, 1997). Storage carbohydrates mainly consist of glucose, such as laminarin and other glucans, while structural heteropolysaccharides (e.g., galactans) such as occurring in algal cell walls can contain a lot of galactose, mannose and rhamnose (McCarthy et al., 1996). Furthermore, an elevated release of polysaccharides by phytoplankton, mostly of gelatinous nature, has been associated with stress situations, such as a deficiency of nutrients, freez- 
ing or fluctuating water potential (Berman-Frank et al., 2007; Bianchi and Canuel, 2011; Borchard and Engel, 2012, 2015; Ittekkot et al., 1981; Krembs et al., 2002; Krembs and Deming, 2008). These exuded polysaccharides are relatively depleted in glucose and galactose and mainly contain acidic sugars, fucose, rhamnose and arabinose in their chemical structure (Borchard and Engel, 2012; Passow, 2002). Even though polysaccharides are ubiquitous in nature, a recent study revealed that the individual sugar pattern is different between algae and terrestrial plants (Hepp et al., 2016) and may allow a source apportionment of carbohydrates in seawater.

Dissolved free carbohydrates (DFCHO) have been found to form another fraction of marine carbohydrates (Engel and Händel, 2011; Ittekkot et al., 1981; Kirchman et al., 2001). DFCHO are considered to be either directly released by phytoplankton cells or be the product of enzymatic degradation of CCHO (Pakulski and Benner, 1994). DFCHO are mostly found in lower concentrations than $\mathrm{CCHO}$, since marine microbes utilize them with high turnover rates (Engbrodt, 2001; Engel and Händel, 2011; Ittekkot et al., 1981; Thornton et al., 2016) as it has been reported for amino acids analogously as well (Kuznetsova and Lee, 2002). From the concentrations of DFCHO, or rather the ratio between CCHO and DFCHO, information about in situ activities of local phytoplankton and bacteria in the seawater can be obtained (Pakulski and Benner, 1994; Sakugawa and Handa, 1985). Recently, correlations between the concentrations of free glucose in Arctic surface water samples and their ice nucleating activity (INA) suggested a potential link between the formation of INA and marine carbohydrates (Zeppenfeld et al., 2019).

At the ocean surface, wind and wave interactions lead to bubble bursting. The emitted sea spray aerosol contains marine carbohydrates, including hydrogels, which contribute to the chemical and physical properties of these particles (Bigg and Leck, 2008; Frossard et al., 2014; Hawkins and Russell, 2010; Rosenørn et al., 2006). They have been detected in particles in different marine environments on Earth, including the North Atlantic, the Arctic and Antarctica (Barbaro et al., 2015; Frossard et al., 2014; Gao et al., 2011, 2012; Leck et al., 2013; Russell et al., 2010). However, understanding the quantitative fluxes of marine carbohydrates from the ocean to the atmosphere is still challenging, since chemical analysis of sugars in seawater strongly suffers from matrix effects, especially caused by sea salt.

The concentrations of individual monosaccharides in seawater, related saline matrices and aerosol particles can be determined with different kinds of chromatographic methods, such as high-performance liquid chromatography and gas chromatography. These methods require a prior derivatization in order to enable the chromatographic separation and detectability of these carbohydrates (Panagiotopoulos and Sempéré, 2005). In the last decades, high-performance anion exchange chromatography coupled to pulsed amperometric detection (HPAEC-PAD) has been established as a re- liable alternative, since it facilitates a sensitive quantification of sugar compounds both in seawater and in airborne particles without a prior derivatization (Iinuma et al., 2009; Panagiotopoulos and Sempéré, 2005; van Pinxteren et al., 2012; Skoog and Benner, 1997). However, the high ionic content in seawater samples strongly affects the chromatographic performance of the HPAEC-PAD and needs to be removed before analysis.

Several procedures are available for the desalination of seawater. The desalination using anion exchange resins AG2$\mathrm{X} 8$ and the cation exchange resin AG50W-X8 exhibits strong drawbacks such as the complete loss of charged sugars (amino sugars, uronic acids) and quite low recovery rate of neutral sugars between $20 \%$ and $80 \%$ depending on the individual monosaccharide (Borch and Kirchman, 1997; Mopper et al., 1992; Rich et al., 1996). The use of silver cartridges (Dionex OnGuard II Ag/H Cartridges) is faster and easier, but requires very expensive consumables and the capacity of removable sea salt per cartridge is strongly limited (Mopper et al., 1992; Panagiotopoulos and Sempéré, 2005). The desalination applying dialysis membranes achieves reproducible and very high recovery rates of hydrolyzable polysaccharides (>90\%). However, this method does not allow the analysis of DFCHO, since these small molecules pass the membrane during dialysis (Engel and Händel, 2011).

Electro-dialysis (ED) is a fast way to remove ions by applying an electrical field. The use of two different chemoselective ion exchange membranes allows the exclusive removal of small anions, or cations, respectively. Hence, uncharged small substances (neutral DFCHO) and macromolecules $(\mathrm{CCHO})$ can, in principle, be recovered in high quantities. Amongst others, ED is being used for the desalination of salty water to generate potable water and the denitrification of wastewater and soil remediation (Gain et al., 2002; Ottosen et al., 2000; Sadrzadeh and Mohammadi, 2008; Tsiakis and Papageorgiou, 2005; Wisniewski et al., 2001). For analytical sample preparation, ED has been reported as a powerful desalination, e.g., for the analysis of DOM and marine neutral DFCHO (Josefsson, 1970; Koprivnjak et al., 2009; Mopper et al., 1980; Vetter et al., 2007; Wirth et al., 2019). However, following biases, which have hitherto not been discussed in this analytical context, can occur during the application of ED and might falsify the determined concentration of the analytes in the sample. In contact with ion exchange membranes, the passive transport of water (osmosis) and solutes with a low molecular weight (diffusion), such as DFCHO, can occur triggered by a concentration gradient between the sample and concentration channels (Galama et al., 2014; Galier et al., 2012). Additionally, the active transport of charged molecules (migration) and water bound to ions in their hydration sphere (electro-osmosis) takes place by operating an electrical field (Galama et al., 2014; Han et al., 2015, 2017). While osmosis and electro-osmosis induce an unavoidable loss of water and hence of the total volume of the sample, diffusion and migra- 
tion of the analytes result in a loss of analyzable molecules. Furthermore, water splitting and associated $\mathrm{pH}$ fluctuations have been reported, when a limiting current is exceeded during an ED desalination (Cowan, 1962; Martí-Calatayud et al., 2018; Ottosen et al., 2000; Vetter et al., 2007).

Within the present study, a novel protocol for the desalination of seawater samples and other saline samples (e.g., ice cores and brine from Arctic sea ice), applying ED and HPAEC-PAD is presented, accounting for the biases described above. With a low need of consumables, this method allows the analysis of monosaccharides with (DCCHO) and without hydrolysis (DFCHO), including the possible determination of free amino sugars and free uronic acids. This developed technique was applied to analyze a diverse set of carbohydrates in different kinds of ambient seawater samples.

\section{Experimental}

\subsection{Chemicals and materials}

Prior to the analysis of carbohydrates in seawater, all used laboratory glassware had been washed with ultrapure water (resistivity $>18.2 \mathrm{M} \Omega \mathrm{cm}$ ) thoroughly and preheated in a muffle furnace at $550^{\circ} \mathrm{C}$ for $4 \mathrm{~h}$. All plastic equipment was first rinsed with $10 \% \mathrm{HCl}$ solution three times and then washed with ultra-pure water another three times. For calibrating the HPAEC-PAD and determining the recovery of individual monosaccharides, a mixed stock solution was prepared from fucose (Roth, $95 \%$ ), galactosamine (Sigma, 99\%), rhamnose (Sigma, $99 \%$ ), arabinose (Sigma, $99 \%$ ), glucosamine (Fluka), galactose (Fluka, 99\%), glucose (99\%), xylose (Fluka, 99\%), mannose (Fluka, 99\%), fructose (Aldrich, 99\%), ribose (Aldrich, $98 \%$ ), muramic acid (Sigma, $95 \%$ ), galacturonic acid (Sigma-Aldrich, $97 \%$ ), glucuronic acid (Sigma, $97 \%$ ), mannuronic acid (Sigma, $90 \%$ ). Synthetic seawater samples were made from commercially available sea salt (Sigma) achieving four solutions with salinities $S$ of 10, 20, 30 and 40 on the practical salinity scale. The salinity and the $\mathrm{pH}$ of water aliquots were measured by using a conductivity meter (pH/Cond 3320, WTW).

\subsection{Field samples}

Seven different seawater samples, one ice core from Arctic sea ice and two brines collected within Arctic ice cores (Table 1) were measured and used for evaluating recovery rates and comparability of the method presented here. These saline samples were collected during different sampling campaigns and stored at $-20^{\circ} \mathrm{C}$. All sampling bottles had been rinsed with dilute hydrochloric acid $(10 \% v / v)$ prior to the campaign. Field blanks (ultra-pure water filled up in sampling bottles during the campaign) were collected during each campaign and treated in the same way as the samples.

\subsection{The ED system}

The centerpiece of the PCCell Micro Bench ED system for small sample volumes consisted of three separated compartments (Fig. 1): the sample compartment was an open chamber that was filled up with $9 \mathrm{~mL}$ of the standard solution or seawater sample. The functionalized anion exchange membrane (quaternary ammonium aliphatic polyether) and cation exchange membrane (sulfonated aromatic polyether) bordered this compartment on both sides. Depending on their chemical properties, the membranes allowed exclusively the migration of either positively or negatively charged ions. For that matter, the anion exchange membrane bordering the sample chamber was oriented to the anode and the cation exchange membrane to the cathode. The contact surface with the sample was $7.8 \mathrm{~cm}^{2}$ for each membrane. For maintaining the conductivity within the system and receiving the sea salt from the sample, the next compartment contained the concentration circuit, a $16 \mathrm{~g} \mathrm{~L}^{-1} \mathrm{NaCl}$ solution (Merck). This concentration was chosen in order to minimize the osmotic water transfer as discussed below. This solution was circulated at a rate of $60 \mathrm{~mL} \mathrm{~min}{ }^{-1}$. Two end membranes on each side divided the concentration circuit from the third compartment containing the electrodes. The end membranes were cation exchange membranes with an increased chemical durability and an additional reinforcement in order to withstand the strong differential pressure within the ED system. The mixed metal oxide (MMO) anode was made of a titanium base body coated with $\mathrm{RuO}_{2}, \mathrm{IrO}_{2}$ and $\mathrm{TiO}_{2}$. The MMO cathode was made of stainless steel. The electrodes were permanently surrounded by a circulating $0.25 \mathrm{M}$ $\mathrm{Na}_{2} \mathrm{SO}_{4}$ (Fluka) electrolyte circuit for avoiding unwanted redox reactions (e.g., the generation of corrosive elemental chlorine from chloride). Spacers were inserted between each membrane for keeping the electrolyte and concentration circuits well mixed. The sample solution was homogenized during each desalination by drawing some liquid into a Pasteur pipette and draining it immediately back to the sample compartment. The electrolyte and the concentration solutions were renewed after every tenth desalination. The maximal electrical current $I_{\max }$ within the ED cell was adjusted by an automatic online adaption of the voltage, which never exceeded $25 \mathrm{~V}$. The maximal current was set on $0.6 \mathrm{~A}$ in order to perform a fast desalination but also to avoid a scaling of the membranes due to water splitting and is discussed more in detail below. The desalination was stopped when the electric current dropped to a value of $0.20 \mathrm{~A}$.

The used ion exchange membranes have a quite long lifetime as long as they are not damaged mechanically. However, very high attention needs to be given to remove residues of previous desalinated samples in order to avoid carry-over phenomena and obtain good reproducibility. Hence, every time before a new sample was desalinated, the sample chamber was always first filled with ultra-pure water for $10 \mathrm{~min}$ 
Table 1. Sampling details of discussed saline samples including seawater (SWS), an ice core (IC) and brine (B). SML stands for surface microlayer (Engel et al., 2017).

\begin{tabular}{lllllll}
\hline $\begin{array}{l}\text { Saline sample } \\
\text { (SS) }\end{array}$ & Location & Sampling date & Campaign & Latitude & Longitude & $\begin{array}{l}\text { Depth } \\
(\mathrm{m})\end{array}$ \\
\hline SWS 1 & Tropical Atlantic & 13 November 2011 & Cabo Verde & $16.935^{\circ} \mathrm{N}$ & $024.915^{\circ} \mathrm{W}$ & 0 (SML) \\
SWS 2 & Tropical Atlantic & 13 November 2011 & Cabo Verde & $16.935^{\circ} \mathrm{N}$ & $024.915^{\circ} \mathrm{W}$ & 2 \\
SWS 3 & Raunefjorden & 16 May 2011 & Raunefjorden & $60.274^{\circ} \mathrm{N}$ & $005.181^{\circ} \mathrm{E}$ & 2 \\
SWS 4 & North Atlantic & 07 May 2012 & ANT-XXVIII-5 & $33.3^{\circ} \mathrm{N}$ & $013.5^{\circ} \mathrm{W}$ & 0 (SML) \\
SWS 5 & Arctic Ocean & 13 July 2017 & PS 106* & $81.229^{\circ} \mathrm{N}$ & $018.744^{\circ} \mathrm{E}$ & 1 \\
SWS 6 & Arctic Ocean & 14 July 2017 & PS 106* & $81.015^{\circ} \mathrm{N}$ & $026.883^{\circ} \mathrm{E}$ & 1 \\
SWS 7 & North Sea & 25 May 2017 & PS 106 & $57.288^{\circ} \mathrm{N}$ & $005.213^{\circ} \mathrm{E}$ & 1 \\
IC 1 & Arctic Ocean & 12 June 2017 & PS 106 & $81.824^{\circ} \mathrm{N}$ & $011.571^{\circ} \mathrm{E}$ & $0-0.8$ \\
B 1 & Arctic Ocean & 12 June 2017 & PS 106 & $81.824^{\circ} \mathrm{N}$ & $011.571^{\circ} \mathrm{E}$ & $0-0.8$ \\
B 2 & Arctic Ocean & 12 June 2017 & PS 106 & $81.824^{\circ} \mathrm{N}$ & $011.571^{\circ} \mathrm{E}$ & $0-1.5$ \\
\hline
\end{tabular}

* Wendisch et al. (2019).

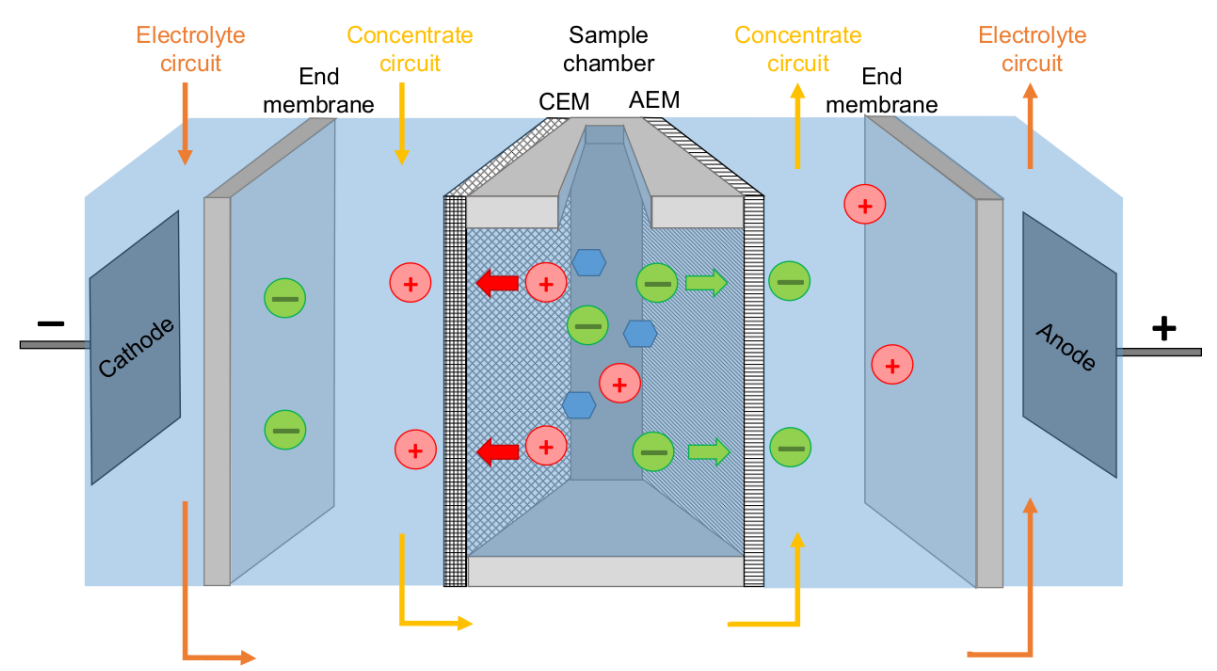

Figure 1. Schematic setup of the used ED cell. Red circles represent cations, green circles anions, and blue hexagons are carbohydrates. CEM and AEM stand for cation exchange membrane and anion exchange membrane, respectively.

and then flushed once with an aliquot of the new sample, which was disposed after.

\subsection{HPAEC-PAD system}

HPAEC-PAD was applied for the analysis of marine carbohydrates in seawater samples. Here, we used an Dionex ICS3000 ion chromatography system coupled to an autosampler (AS-1) as it has been already described for the analysis of saccharidic biomass burning markers in atmospheric particles (Iinuma et al., 2009). Several neutral monosaccharides, amino sugars and uronic acids were separated on a Dionex CarboPac PA20 analytical column $(3 \times 150 \mathrm{~mm})$ combined with a Dionex CarboPac PA20 guard column $(3 \times 30 \mathrm{~mm})$. The column oven temperature was maintained at $30^{\circ} \mathrm{C}$. The separation of these saccharides was conducted by applying the gradient profile shown in Table 2, which was an adaption of Meyer et al. (2008). Neutral and amino sugars were eluted in $4 \mathrm{mM} \mathrm{NaOH}$ within the first $19 \mathrm{~min}$. By adding sodium acetate, sugar acids eluted. At the same time, organic and inorganic contaminants were flushed from the column. After the removal of the remaining acetate by $250 \mathrm{mM} \mathrm{NaOH}$, the system was equilibrated with $4 \mathrm{mM} \mathrm{NaOH}$ for the next sample injection. The flow rate of the eluent was $0.5 \mathrm{~mL} \mathrm{~min}^{-1}$. The retention times, peak widths and resolution factors of the measured monosaccharides are shown in Table 3. For the injection of a sample aliquot, a $25 \mu \mathrm{L}$ loop was used. Each sample was measured in duplicate and each standard in triplicate. Limits of detection (LODs) of individual monosaccharides ranged from 2 to $12 \mathrm{nM}$, which is in good agreement with reported data (Engel and Händel, 2011; Panagiotopoulos and Sempéré, 2005).

For the preparation of eluents A-D, filtered ultra-pure water (resistivity $>18.2 \mathrm{M} \Omega \mathrm{cm}$ ) was degassed with helium for 20 min. Eluents A and B were made by adding a defined 
Table 2. Gradient profile applied on the CarboPac PA20 column during HPAEC-PAD analysis.

\begin{tabular}{lrrrr}
\hline $\begin{array}{l}\text { Time } \\
(\mathrm{min})\end{array}$ & $\begin{array}{r}\% \mathrm{~A} \\
(250 \mathrm{mM} \mathrm{NaOH})\end{array}$ & $\begin{array}{r}\% \mathrm{C} \\
(20 \mathrm{mM} \mathrm{NaOH})\end{array}$ & $\begin{array}{r}\% \mathrm{D} \\
(1 \mathrm{M} \mathrm{Na} \text { acetate/ } \\
250 \mathrm{mM} \mathrm{NaOH})\end{array}$ & \\
\hline 0 & & & 0 & 80 \\
19 & 0 & 20 & 0 & 80 \\
20 & 0 & 20 & 15 & 80 \\
35 & 5 & 0 & 15 & 80 \\
38 & 5 & 0 & 40 & 40 \\
39 & 20 & 0 & 0 & 0 \\
44 & 100 & 0 & 0 & 0 \\
45 & 100 & 0 & 0 & 80 \\
78 & 0 & 20 & 0 & 80 \\
\hline
\end{tabular}

Table 3. Averaged peak characteristics of monosaccharide standards separated by the presented elution averaged over 24 runs. Resolution factors are calculated between a peak and the following peak in the chromatogram.

\begin{tabular}{lrcr}
\hline & $\begin{array}{r}\text { Retention } \\
\text { time }(\mathrm{min})\end{array}$ & $\begin{array}{r}\text { Peak width } \\
(\mathrm{min})\end{array}$ & $\begin{array}{r}\text { Resolution } \\
\text { factor }\end{array}$ \\
\hline Fucose & $3.79 \pm 0.01$ & 0.27 & 10.5 \\
Galactosamine & $7.28 \pm 0.01$ & 0.40 & 1.0 \\
Rhamnose & $7.70 \pm 0.02$ & 0.42 & 1.1 \\
Arabinose & $8.15 \pm 0.02$ & 0.42 & 2.2 \\
Glucosamine & $9.23 \pm 0.02$ & 0.56 & 2.1 \\
Galactose & $10.33 \pm 0.02$ & 0.51 & 2.8 \\
Glucose & $11.81 \pm 0.03$ & 0.56 & 3.4 \\
Xylose & $13.89 \pm 0.03$ & 0.65 & 0.8 \\
Mannose & $14.43 \pm 0.04$ & 0.77 & 2.8 \\
Fructose & $16.52 \pm 0.05$ & 0.75 & 2.0 \\
Ribose & $18.20 \pm 0.05$ & 0.93 & 13.2 \\
Muramic acid & $25.84 \pm 0.01$ & 0.23 & 9.0 \\
Galacturonic acid & $29.27 \pm 0.02$ & 0.53 & 4.6 \\
Glucuronic acid & $31.49 \pm 0.02$ & 0.45 & 2.8 \\
Mannuronic acid & $32.83 \pm 0.02$ & 0.49 & \\
\hline
\end{tabular}

volume of low-carbonate $\mathrm{NaOH}$ solution (Fisher Chemical, $50 \% w / w)$ to the degassed water. Eluent $\mathrm{C}$ was prepared by dissolving sodium acetate (Thermo Scientific, anhydrous) in ultra-pure water, filtering it through a nylon membrane $(0.2 \mu \mathrm{m}$, Thermo Scientific), degassing the solution with helium for $20 \mathrm{~min}$ and adding the corresponding volume of $\mathrm{NaOH}$ solution.

\subsection{Protocol for the analysis of DFCHO and DCCHO in seawater and other saline samples}

Stored frozen samples were defrosted in a fridge at $4{ }^{\circ} \mathrm{C}$. A total of $9 \mathrm{~mL}$ of the filtered sample $(0.2 \mu \mathrm{m}$, Millex, PTFE) was desalinated with ED as described above. At the end of each desalination, electro-(osmotic) water loss was replenished with ultra-pure water and mixed thoroughly. In order to analyze free amino sugars or uronic acids, $\mathrm{pH}$ could be adapted with concentrated $\mathrm{HCl}$ or $1 \mathrm{M} \mathrm{NaOH}$.

A concentration step using a vacuum concentrator (MiVac) at $55^{\circ} \mathrm{C}$ allowed the detection of expected DFCHO concentrations in seawater. For this purpose, a round-bottom glass vial was filled with an aliquot of $6 \mathrm{~mL}$ desalted sample, which was weighed empty and filled. After reaching a volume of approximately $600 \mu \mathrm{L}$, the glass vial was weighed again (in order to calculate the concentration factor) and the concentrated aliquot was pipetted in the autosampler vial for HPAEC-PAD analysis. This step allowed a decrease of LOD by a factor of 10 . Each sample was prepared and measured in duplicate.

In order to measure DCCHO, marine polysaccharides need to be cleaved into their monomeric compounds by acid hydrolysis. We applied the optimized conditions described by Engel and Händel (2011) with slight modifications. An aliquot of $1 \mathrm{~mL}$ desalted sample was hydrolyzed with hydrochloric acid $(\mathrm{HCl}$ concentration in sample of $0.8 \mathrm{M})$ in pre-heated $\left(550^{\circ} \mathrm{C}, 4 \mathrm{~h}\right)$ glass ampules for $20 \mathrm{~h}$ at $100^{\circ} \mathrm{C}$. Neutralization was performed by evaporating all liquid under vacuum at $55^{\circ} \mathrm{C}$ until dryness. The dry residue was dissolved in $700 \mu \mathrm{L}$ ultra-pure water, treated with a vortex homogenizer (IKA MS 3 basic) and filled in the autosampler vial for HPAEC-PAD analysis. Each sample was prepared and measured in duplicate.

\subsection{Parameter optimization and assessment of method}

\subsubsection{Impact of osmosis and electro-osmosis during ED desalination}

For quantifying the loss of water in the sample due to osmosis and electro-osmosis, a synthetic sea salt solution was pipetted into the desalination chamber, which was desalinated for $0,5,10,15,20$ and 25 min with a maximal voltage of $25 \mathrm{~V}$ and a maximal current of $0.6 \mathrm{~A}$. After the lapse of time, the total remaining volume was pipetted quantitatively into a glass vial and weighed (Mettler Toledo, XS105 Dual- 
Range). These measurements were repeated in triplicate for four different sea salt solutions (with $S$ of 10, 20, 30 and 40). The recovery of the sample mass was calculated as the ratio between the mass after the corresponding desalination time and the averaged mass at $0 \mathrm{~min}$.

\subsubsection{Recovery of DFCHO within the ED membrane system}

Standard addition experiments with seawater samples were performed for quantifying the recovery of monosaccharides due to diffusion and migration under consideration of all matrix effects. For that reason, sample 7 was filtered $(0.2 \mu \mathrm{m}$, Millex, PTFE) and spiked with a sugar standard mix (neutral sugars, amino sugars, uronic acids) resulting in a concentration increase of 10 and $100 \mu \mathrm{gL}^{-1}$. These samples were desalinated using $\mathrm{ED}\left(I_{\max }=0.6 \mathrm{~A}\right.$, stop at $\left.0.2 \mathrm{~A}\right)$. At the end of each run, (electro-)osmotic water loss was either replenished or not, and the sample directly measured with the HPAEC-PAD. These measurements were repeated in triplicate for each concentration. In order to account for possible wasting phenomena, repetitions were performed with new membranes and membranes which already had been used for some time before. Given recovery rates for neutral monosaccharides are the average of the results for 10 and $100 \mu \mathrm{gL}^{-1}$. For sugar acids and amino sugars, only the averaged recovery rates for $100 \mu \mathrm{gL}^{-1}$ are given for avoiding determinations close to the LOD.

In order to investigate the influence of $\mathrm{pH}$ on the migration of charged monosaccharides, this experiment was repeated for three different $\mathrm{pH}$ values. At $\mathrm{pH}=8$ (natural $\mathrm{pH}$ of seawater), $\mathrm{pH}$ of 1.5 (acidified with concentrated $\mathrm{HCl}$ ) and $\mathrm{pH}$ of 11 (addition of $1 \mathrm{M} \mathrm{NaOH}$ ). Since high $\mathrm{pH}$ in seawater leads to precipitation of hydroxides of alkaline earth metals, additional filtering $(0.2 \mu \mathrm{m})$ was performed for these runs.

\subsection{Recovery of CCHO within the ED membrane system}

Recovery experiments were performed with solutions and a suspension of the polysaccharide standards sodium alginate (Aldrich), laminarin from Laminaria digitate (Sigma) and cellulose powder from spruce (Fluka) at natural $\mathrm{pH}$. Stock solutions were added to filtered sample SWS 7 resulting in concentrations of $10 \mathrm{mg} \mathrm{L}^{-1}$. Aliquots of $1 \mathrm{~mL}$ with and without desalinations were hydrolyzed $(\mathrm{HCl} 0.8 \mathrm{M}$, $100{ }^{\circ} \mathrm{C}, 20 \mathrm{~h}$ ) and neutralized by evaporation of the volatile liquid with the vacuum concentrator $\left(55^{\circ} \mathrm{C}\right)$ until dryness. The residue was reconstituted in $700 \mu \mathrm{L}$, treated with a vortex homogenizer (IKA MS 3 basic) and filled in the autosampler vial for HPAEC-PAD analysis. Recovery rates were calculated as a ratio between the determined monosaccharide concentrations after hydrolysis of the standard solutions with and without desalination.
In order to compare our method on the recovery of DCCHO with another established method, aliquots of four filtered $(0.2 \mu \mathrm{m}$, Millex, PTFE) seawater samples were treated following the ED protocol presented here and the protocol by Engel and Händel (2011) using membrane desalination, an acid hydrolysis with $\mathrm{HCl}\left(0.8 \mathrm{M}, 100^{\circ} \mathrm{C}, 20 \mathrm{~h}\right)$, neutralization by evaporation (nitrogen, $50^{\circ} \mathrm{C}$ ) and an elution on a Dionex CarboPac PA10 column.

\section{Results and discussion}

A reproducible quantification of carbohydrates in seawater samples using HPAEC-PAD requires prior removal of sea salt. Here, we present ED as a reliable desalination method, its parameter optimization and the discussion of arising phenomena resulting in a protocol for the analysis of marine carbohydrates.

\subsection{Kinetics and efficiency of desalination}

During the desalination of seawater by ED, anions and cations migrate through an electrical field and pass chemoselective membranes. Depending on their electrical charge, they move either to the positively charged anode or to the negatively charged cathode. In this process, the salt flux through the membranes $j_{\mathrm{S}}\left(\mathrm{mol} \mathrm{m}^{-2} \mathrm{~s}^{-1}\right)$, which determines the desalination time, is proportional to the applied electrical current I (Han et al., 2017; Vanoppen et al., 2015). Figure 2 shows the current within the used ED system and the salinity of the seawater sample during a typical desalination of an artificial seawater sample $(S=40)$ for two different applied maximal currents $I_{\max }$ within the system. For almost the entire desalination run, the current $I$ was maintained at $I_{\max }$ due to automatic adjustment of the voltage. During this time, the salt flux was approximately constant. Towards the end of the desalination, when almost all salt ions were removed, the current dropped down and the salt flux became lower. Since a direct salinity measurement was not possible in the sample chamber without contaminating the sample, the end of each desalination was defined, when the current $I$ reached a value of $0.2 \mathrm{~A}$. At this point, the salinity of the sample typically ranged between 0.2 and 0.4 , which was found to be sufficiently low for the carbohydrate analysis at the HPAEC-PAD. This reduction in salinity represents an overall desalination of more than $99 \%$ of the initial salt concentration. A desalination reaching a salinity below 0.1 was possible but was not necessary for this application and would have resulted in longer desalination times. Consequently, for minimizing the required desalination time, a high $I_{\max }$ is favorable.

However, it was observed that the application of an $I_{\max }$ of more than $0.8 \mathrm{~A}$ during the desalination, resulted in a large $\mathrm{pH}$ increase and a white precipitation in the (synthetic) seawater solution, apparently due to the formation of hydroxides of alkaline earth metals. This uncontrolled precip- 


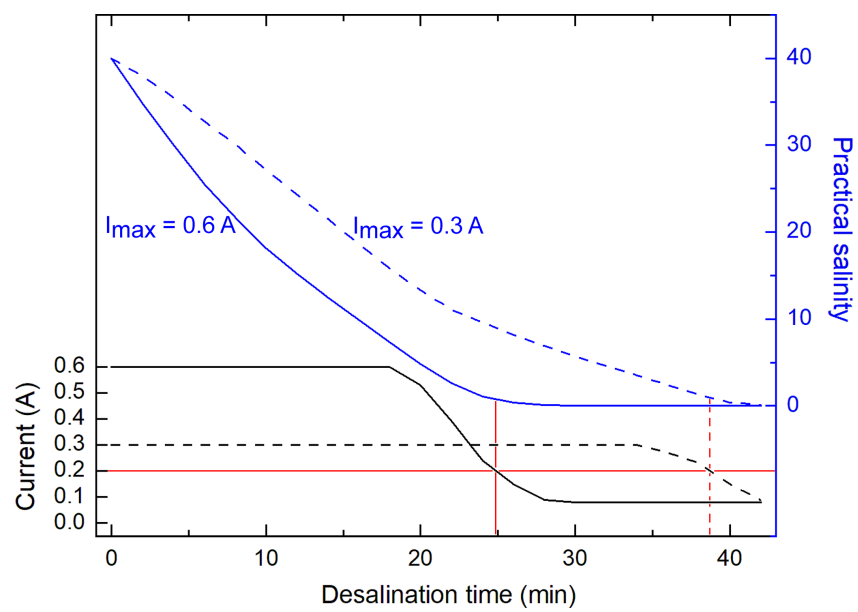

Figure 2. Measured current within the ED system and salinity of a synthetic sea water sample $(S=40)$ versus desalination time with two different maximal applied currents $I_{\max }(0.6 \mathrm{~A}$ solid line, $0.3 \mathrm{~A}$ dashed line). The red line represents the current and the corresponding salinity when desalination was stopped.

itation strongly disturbed the efficiency of the desalination and the reproducibility of the carbohydrate measurements and caused a scaling of the membranes. Previous studies explained these unfavorable changes of $\mathrm{pH}$ by a strong concentration polarization at the membrane's surface leading to water splitting to $\mathrm{H}^{+}$and $\mathrm{OH}^{-}$ions, when a certain limiting current is exceeded. This phenomenon has been preferably observed at anion exchange membranes with quaternary amino groups in the presence of divalent cations, such as $\mathrm{Mg}^{2+}$ and $\mathrm{Ca}^{2+}$ (Cowan, 1962; Martí-Calatayud et al., 2018; Ottosen et al., 2000). The precipitation exclusively occurred when (synthetic) seawater was desalinated and not during the desalination of $\mathrm{NaCl}$ standard solutions. This finding shows the importance of performing parameter optimization tests with synthetic seawater standards that include all important seawater constituents such as divalent cations. In summary, the optimum maximal current $I_{\max }$ of $0.6 \mathrm{~A}$ was found for the used ED system for avoiding scaling effects and performing desalination as fast as possible.

\subsection{Possible biases during the application of ED}

\subsubsection{Osmotic and electro-osmotic transport of water}

Osmosis describes the passive transport of free water molecules through a partially permeable membrane caused by large differences of the osmotic pressures between the concentrate circuit and the sample solution (Sata, 2004). The direction and the quantity of the water transport depend on the residence time $t_{\mathrm{R}}$ of the sample solution within the membrane system, the difference between the concentrations of solutes in the sample solution and the concentration $\operatorname{circuit}\left(c_{\mathrm{S}}-c_{\mathrm{c}}\right)$ and membrane specific parameters, such as the osmotic water transfer coefficient the membrane area and the membrane thickness (Galama et al., 2014). The quantitative effect of osmosis can be reduced by minimizing $t_{\mathrm{R}}$ and $\left(c_{\mathrm{S}}-c_{\mathrm{c}}\right)$. Hence, $c_{\mathrm{c}}$ was set at $16 \mathrm{~g} \mathrm{NaClL}^{-1}$, which is approximately in the middle between the concentrations of a typical seawater sample before (salinity of 30-39) and after the desalination (salinity of $0.2-0.4$ ) for balancing the positive and negative contribution of osmosis on the total sample volume during a typical desalination.

In aqueous solutions, water molecules form a hydration shell around ions (Ohtaki and Radnai, 1993). Whenever ions pass through membranes during $\mathrm{ED}$, a cotransport of these hydrating water molecules occurs, known as electro-osmosis (Galama et al., 2014). The electro-osmotic water transfer $j_{\mathrm{W}}$ $\left(\mathrm{m}^{3} \mathrm{~m}^{-2} \mathrm{~s}^{-1}\right)$ is proportional to the salt flux $j \mathrm{~s}$ in the system and can be expressed by formula (1) with the molar volume of water $V_{\mathrm{M}}\left(1.8 \times 10^{-5} \mathrm{~m}^{3} \mathrm{~mol}^{-1}\right)$ and the salt hydration number $n_{\mathrm{H}}$ (mol water $\mathrm{mol}^{-1}$ salt) (Galier and Balmann, 2015; Han et al., 2015).

$j_{\mathrm{W}}=n_{\mathrm{H}} \cdot V_{\mathrm{M}} \cdot j_{\mathrm{S}}$

The salt hydration number of $\mathrm{NaCl}$, as the major compound of sea salt, has been reported with values between 11 and 14 (Han et al., 2015; Rutgers and Hendrikx, 1962; Singlande et al., 2006; Walker et al., 2014). Assuming a $\mathrm{NaCl}$ concentration of $30 \mathrm{~g} \mathrm{~L}^{-1}$ and $n_{\mathrm{H}}$ to be 14 , a maximal reduction of the sample volume by $13 \%$ due to electro-osmosis was expected, in addition to osmosis.

The recovery of the sample volume due to electro-osmosis and osmosis during the desalination was characterized for four different salinities for the used ED system (Fig. 3). During the active removal of sea salt, electro-osmosis is the dominating force causing the water loss in the sample. The electro-osmotic water loss is continual as long as the salt flux stays constant. However, in the final stages of each desalination, the salt flux decreases and consequently the electroosmotic water transfer decreases, too. For a synthetic seawater sample with a salinity of $30,84 \%$ of sample mass was recovered. This is in good agreement with the estimation mentioned above considering a small additional contemporaneous contribution of osmosis. Once the sea salt is removed, osmotic water transfer remained at a constant rate of approximately $0.1 \% \mathrm{~min}^{-1}$.

The overall water loss resulting from osmosis and electroosmosis needs to be taken into account since it falsifies the determined concentrations of marine carbohydrates. For its compensation, the chamber was replenished with ultra-pure water at the end of each desalination until the initial sample volume was reached. This procedure was performed with a maximal overall error of $0.5 \%$. 


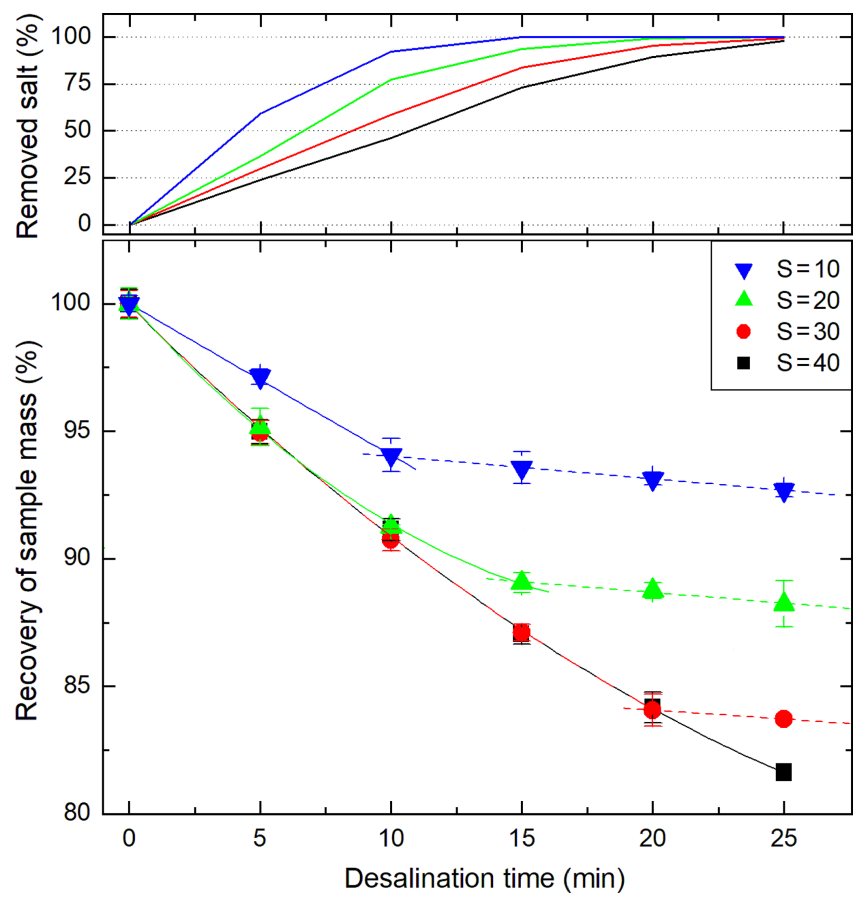

Figure 3. Combined effect of electro-osmosis and osmosis (solid lines) and osmosis (dashed lines) on the recovery of sample mass as a function of the desalination time within the described membrane system $\left(I_{\max }=0.6 \mathrm{~A}, c_{\mathrm{c}}=16 \mathrm{~g} \mathrm{NaCl} \mathrm{L}^{-1}\right)$ for artificial sea salt solutions with four different initial salinities.

\subsubsection{Analysis and recovery of DFCHO in seawater samples}

The recovery of neutral monosaccharides during ED is impacted by diffusion and convection processes (Galier and Balmann, 2015). Additionally, free amino sugars and uronic acids migrate through an electrical field due to their charge and pass the ion exchange membranes. Recovery tests were performed with standard solutions spiked to a seawater samples with concentrations, which have been typically reported for seawater samples before (Kirchman et al., 2001; Mopper et al., 1980; Skoog et al., 1999; Zeppenfeld et al., 2019). Recovery rates of neutral sugars (Glc, Man, Xyl, Gal, Ara, Fuc, Rha, Fru) ranged between $95 \%$ and $98 \%$ at the natural $\mathrm{pH}$ of seawater (approximately $\mathrm{pH}=8$ ) (Table 4). Hence, the overall impact of diffusion and convection on the recovery of monosaccharides seems to be quite low for the short contact time with these membranes. However, a higher loss of neutral monosaccharides due to diffusion was observed, when the sample solution remained within the membrane system for a longer period of time, which calls for a fast desalination. This is in agreement with Vanoppen et al. (2015), who concluded that diffusion and affinity for the membrane are the main drivers for losses of uncharged, low-molecular organics during a ED desalination. An overestimation of the determined concentrations was avoided by performing a correc-
Table 4. Recovery of individual free monosaccharides (neutral, amino sugars, uronic acids) after desalination with ED including correction of (electro-)osmotic water loss.

\begin{tabular}{lccc}
\hline Monosaccharide & \multicolumn{3}{c}{ Recovery rate (\%) } \\
\cline { 2 - 4 } & $\mathrm{pH}_{\text {Start }}=1.5$ & $\begin{array}{c}\mathrm{pH}_{\text {Start }}=8 \\
\text { (seawater) }\end{array}$ & $\mathrm{pH}_{\text {Start }}=11$ \\
\hline Galactose & $97.6 \pm 1.0$ & $96.0 \pm 0.9$ & $97.2 \pm 1.4$ \\
Fucose & $97.2 \pm 2.4$ & $97.9 \pm 1.6$ & $97.0 \pm 1.0$ \\
Glucose & $96.9 \pm 1.5$ & $97.2 \pm 1.4$ & $97.1 \pm 2.1$ \\
Mannose & $95.8 \pm 1.8$ & $95.8 \pm 1.3$ & $95.8 \pm 2.1$ \\
Xylose & $95.6 \pm 2.3$ & $95.9 \pm 2.2$ & $95.2 \pm 2.0$ \\
Rhamnose & $93.5 \pm 1.6$ & $94.2 \pm 1.6$ & $95.1 \pm 1.4$ \\
Arabinose & $93.4 \pm 2.3$ & $95.1 \pm 1.1$ & $94.5 \pm 1.9$ \\
Fructose & $89.3 \pm 3.4$ & $94.6 \pm 2.7$ & $94.1 \pm 2.2$ \\
Glucuronic acid & $48.7 \pm 2.7$ & $31.0 \pm 1.9$ & n.d. \\
Mannuronic acid & $44.9 \pm 0.6$ & $25.0 \pm 1.9$ & n.d. \\
Muramic acid & $24.7 \pm 1.7$ & n.d. & n.d. \\
Glucosamine & $1.5 \pm 0.4$ & $18.9 \pm 1.2$ & $59.0 \pm 3.2$ \\
Galactosamine & $1.2 \pm 0.3$ & $15.9 \pm 1.5$ & $58.0 \pm 3.4$ \\
\hline
\end{tabular}

n.d.: not determined.

tion of the water loss in the end of each desalination. Charged monosaccharides were found with much lower recoveries of $25 \%-31 \%$ for uronic acids and $16 \%-19 \%$ for amino sugars at $\mathrm{pH}=8$. This is due to their weak acidic/basic properties $\left(\mathrm{pK}_{\mathrm{a}}\right.$ (amino sugars) of 7.6-8.5 (Bichsel and von Gunten, 2000; Sinnott, 2007), $\mathrm{pK}_{\mathrm{a}}$ (uronic acids) of 3.3-3.5 (Kohn and Kovác, 1978)) and hence their partially ionic state, which makes them migrate through the electrical field. However, a low $\mathrm{pH}$ can protonate the carboxylic group of uronic acids and a high $\mathrm{pH}$ deprotonates the amino group of amino sugars for reducing this effect. Here, we found that an initial $\mathrm{pH}$ of 1.5 before desalination could increase the recovery of free uronic acids up to $45 \%-49 \%$, while a high $\mathrm{pH}$ of 11 resulted into a higher recovery of free amino sugars up to $58 \%-59 \%$. The recovery of neutral sugars seemed to be quite unaffected within the range of the tested $\mathrm{pH}$, with the exception of fructose, which was $89 \%$ recovered at $\mathrm{pH}$ of 1.5 , certainly due to its instability within acid conditions.

\subsubsection{Analysis and recovery of $\mathrm{CCHO}$ in seawater samples with standard polysaccharides}

Recovery experiments with standard solutions of common polysaccharides were performed with and without desalination by ED. The neutral, water-soluble polysaccharide laminarin was recovered with $91.0 \pm 5.4 \%$. The acidic polysaccharide alginic acid was recovered with $93.2 \pm 5.3 \%$. Even though alginic acid might move within the electrical field due to its acidic molecular structure, its molecular weight does not allow passing the membrane and it does not leave the sample solution. Standard desalination experiments with a suspension of the water insoluble cellulose as a representative of PCCHO resulted in much lower recoveries of 
$48 \pm 19 \%$. The reason for this high, less reproducible loss of polysaccharides was likely sedimentation within the sample chamber. Engel and Händel (2011) described adsorption processes during the desalination with dialysis membranes and tackled this problem with sonification of the membranes. However, sonification could not be applied in our apparatus. In this study, flushing the chamber several times with a defined volume of ultra-pure water after desalination and reuniting the washing water with the desalinated sample could increase the yield of cellulose up to $85.2 \pm 6.9 \%$ under consideration of dilution factors. This procedure was not found to be feasible, since a dilution of a natural sample reduces the sensitivity of low concentrated sugars in seawater in the analysis by HPAEC-PAD. Rather, we recommend ED only for the application to filtered samples (DCCHO), while PC$\mathrm{CHO}$ might be better analyzed from filters after filtration.

\subsubsection{Comparison of ED and dialysis method for the determination of DCCHO in seawater samples}

In order to evaluate the presented procedure for the analysis of DCCHO, comparison studies were performed measuring four ambient seawater samples (SWSs 1-4) with the established membrane dialysis protocol after Engel and Händel (2011) and with the method presented here. Figure 4 shows a comparison of the results of the individual monosaccharides after hydrolysis with $\mathrm{HCl}$. The slope of the regression line using all sugar data together with the determination coefficient $\left(R^{2}=0.89\right)$ indicates a good overall agreement between both methods. Major concentrated sugars, such as glucose, galactose and xylose/mannose, were determined at similar concentrations. Furthermore, good agreement was observed for minor concentrated sugars, such as fucose and galactosamine. Discrepancies were found for rhamnose and arabinose, which was overestimated by the ED method, and glucosamine, which was determined at lower concentrations. These variations might be explained by statistical uncertainties or co-elution of unknown substances. In summary, the method presented here using ED has shown to be in good agreement with the established membrane dialysis method regarding the analysis of DCCHO. In addition, the ED offers the major advantage of analyzing the full spectrum of DFCHO as well - which comprise a group of hardly investigated but potentially important marine compounds.

\subsection{Chromatographic performance with HPAEC-PAD after desalination}

Several kinds of saline samples were desalinated with ED and analyzed on the CarboPac PA20 column. Figure 5 shows some examples for DFCHO and DCCHO chromatograms in a brine and a seawater sample after desalination with ED. The insufficient chromatographic separation of mannose and xylose using previous kinds of analytical columns has been frequently described in literature (Borch and Kirchman,

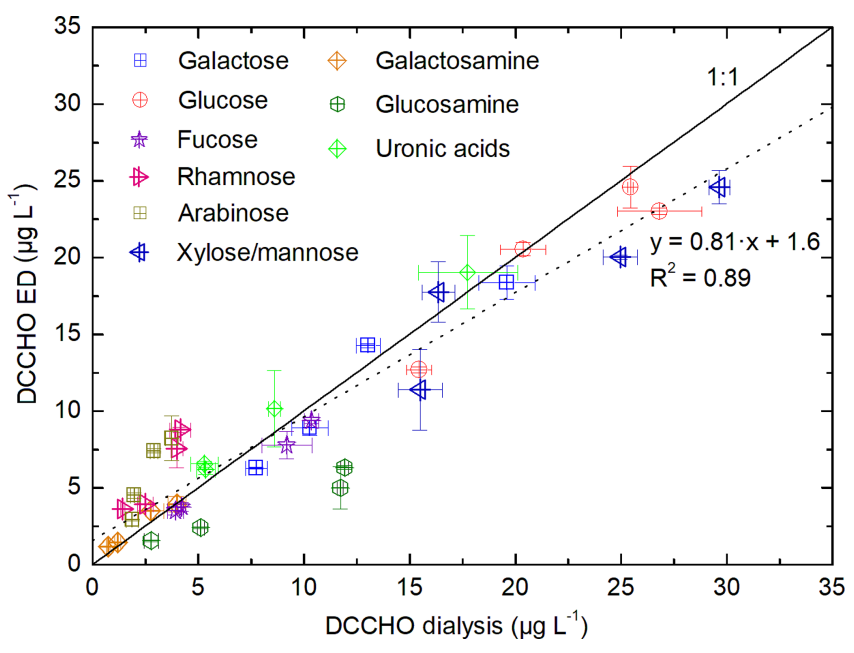

Figure 4. Determined monosaccharide concentrations in four seawater samples (SWSs 1-4) after hydrolysis (DCCHO) comparing the desalination by dialysis (Engel and Händel, 2011) and ED (presented in this study). The solid line represents the line of equality. The dotted line represents the regression line between the data of both methods.

1997; Engbrodt, 2001; Engel and Händel, 2011; Kirchman et al., 2001). Therefore, xylose and mannose have been reported as sum concentrations frequently. The elution of the sugars on a CarboPac PA20 column, applied in the present study, strongly improved the separation between the both sugars mannose and xylose (resolution factor of 0.8 ), and allowed the individual determination of these two sugars. However, most of the analyzed samples showed high concentrations of xylose, which strongly overlapped the smaller peak of mannose. For these cases, we kept reporting a sum value for Xyl/Man.

\subsection{DFCHO and DCCHO in saline field samples from different regions}

Several samples were analyzed on DFCHO and DCCHO (Tables 5 and 6). In both sugar fractions, glucose was the most abundant monosaccharide, as it has been reported before (Panagiotopoulos and Sempéré, 2005). In some of the samples, free fructose could be determined reaching concentrations comparable to glucose. However, fructose cannot be determined in DCCHO, since hydrolysis leads to complete destruction of this sugar. High DFCHO was found in the samples from the Arctic including brine and ice core samples reaching up to $118 \mathrm{nM}$ in comparison to seawater samples from the Atlantic (11-15 nM). However, a clear regional trend could not be identified for DCCHO with concentrations, ranging between 260 and $1410 \mathrm{nM}$. Traces of free amino sugars and uronic acids were found after neutral desalinations. However, a stronger enrichment is required in order to determine them quantitatively and will be the focus of further studies. 
Table 5. Molar percentages of individual neutral monosaccharides within DFCHO in seawater, Arctic brine and ice core samples. $<$ LOD stands for below detection limit.

\begin{tabular}{llllllllr}
\hline & Glc & Gal & Xyl/Man & Rha & Fuc & Ara & Fru & Total DFCHO \\
\cline { 2 - 6 } & \multicolumn{7}{c}{ mol\% } & nM \\
\hline SWS 1 & 57 & 8 & $<$ LOD & $<$ LOD & 7 & 8 & 20 & 15 \\
SWS 2 & 52 & $<$ LOD & $<$ LOD & $<$ LOD & $<$ LOD & $<$ LOD & 48 & 14 \\
SWS 3 & 80 & $<$ LOD & 15 & $<$ LOD & $<$ LOD & 5 & $<$ LOD & 11 \\
SWS 4 & 87 & $<$ LOD & 5 & $<$ LOD & $<$ LOD & 8 & $<$ LOD & 14 \\
SWS 5 & 89 & 3 & 3 & $<$ LOD & $<$ LOD & 4 & $<$ LOD & 35 \\
SWS 6 & 16 & 8 & 22 & $<$ LOD & 34 & 20 & $<$ LOD & 27 \\
IC 1 & 50 & 6 & 2 & 3 & 15 & $<$ LOD & 25 & 118 \\
B 1 & 23 & 27 & 13 & 8 & 29 & $<$ LOD & $<$ LOD & 15 \\
B 2 & 85 & 2 & 3 & 2 & 6 & 1 & $<$ LOD & 53 \\
\hline
\end{tabular}

Table 6. Molar percentages of individual monosaccharides within DCCHO in seawater, Arctic brine and ice core samples. < LOD stands for below detection limit.

\begin{tabular}{|c|c|c|c|c|c|c|c|c|c|c|c|}
\hline & Glc & Gal & Xyl/Man & Rha & Fuc & Ara & GalN & GluN & Gal-ac & Gluc-ac & \multirow{2}{*}{$\begin{array}{r}\text { Total DCCHO } \\
\mathrm{nM}\end{array}$} \\
\hline \multicolumn{11}{|c|}{$\mathrm{mol} \%$} & \\
\hline SWS 1 & 20 & 15 & 22 & 7 & 7 & 8 & 3 & 4 & 12 & 3 & 680 \\
\hline SWS 2 & 25 & 12 & 24 & 8 & 7 & 7 & 2 & 3 & 11 & 1 & 290 \\
\hline SWS 3 & 20 & 14 & 21 & 9 & 10 & 9 & 3 & 6 & 7 & 2 & 580 \\
\hline SWS 4 & 31 & 12 & 26 & 5 & 6 & 7 & 2 & 3 & 6 & 2 & 410 \\
\hline SWS 5 & 84 & 3 & 2 & 2 & 2 & 2 & 1 & 1 & $<$ LOD & 3 & 1410 \\
\hline SWS 6 & 48 & 7 & 10 & 4 & 2 & $<$ LOD & 2 & 4 & 15 & 7 & 260 \\
\hline IC 1 & 54 & 9 & 11 & 1 & $<$ LOD & 1 & 2 & 1 & 10 & 10 & 330 \\
\hline B 1 & 47 & 11 & 13 & 4 & 4 & 3 & 3 & 5 & $<$ LOD & 10 & 420 \\
\hline B 2 & 65 & 8 & 10 & 3 & 4 & 1 & 2 & 3 & $<$ LOD & 3 & 640 \\
\hline
\end{tabular}

\section{Summary and conclusion}

In this study, a novel protocol was presented for the analysis of both DFCHO and DCCHO in saline aqueous samples by applying HPAEC-PAD with prior desalination by ED. Recovery rates for neutral monosaccharides ranged between $95 \%$ and $98 \%$. By adjusting $\mathrm{pH}$, charged monosaccharides such as free amino sugars and uronic acids could be recovered with $58 \%-59 \%$ at $\mathrm{pH}=11$ and $45 \%-49 \%$ at $\mathrm{pH}=$ 1.5 , respectively. Dissolved polysaccharide standards, such as laminarin and alginic acid, showed good recovery rates of $91 \%-93 \%$, while a suspension of insoluble cellulose was quite difficult to recover reproducibly. Hence, ED for carbohydrate analysis is recommended to be used for filtered samples or for samples with a low amount of particulate matter. In this study, the osmotic and electro-osmotic loss of water was considered in order to avoid an overestimation of the determined concentrations. In seawater from different locations, Arctic brine and sea ice core samples, DCCHO was found in concentrations between 260 and $1410 \mathrm{nM}$. DFCHO ranged in much lower concentrations of $11-118 \mathrm{nM}$. Within both DFCHO and DCCHO, the most dominant monosaccharide was glucose, followed by other neutral sugars.
In this study, the successful application of ED in combination with HPAEC-PAD for the analysis of marine carbohydrates (both free and combined) in marine matrices, such as seawater, ice cores and brine, could be demonstrated. The application of ED for other more salt-sensitive analyses should be the focus of further research, e.g., the reported interference of suspended sea spray aerosol in Arctic snow samples during the quantification of insoluble light-absorbing impurities such as black carbon and dust performed via nebulization. Hence, this developed method has the potential to contribute strongly in further research studies understanding biogeochemical processes in the oceans and related saline matrices and sea-air exchange processes, especially for studying hotspot regions of climate change, such as the Arctic.

Data availability. All data are available on the public PANGAEA repository; https://doi.pangaea.de/10.1594/PANGAEA.910575 (Zeppenfeld et al., 2020).

Author contributions. SZ wrote the manuscript with contributions from $\mathrm{MvP}, \mathrm{HH}$ and $\mathrm{AE}$. SZ and $\mathrm{MvP}$ collected seawater sam- 

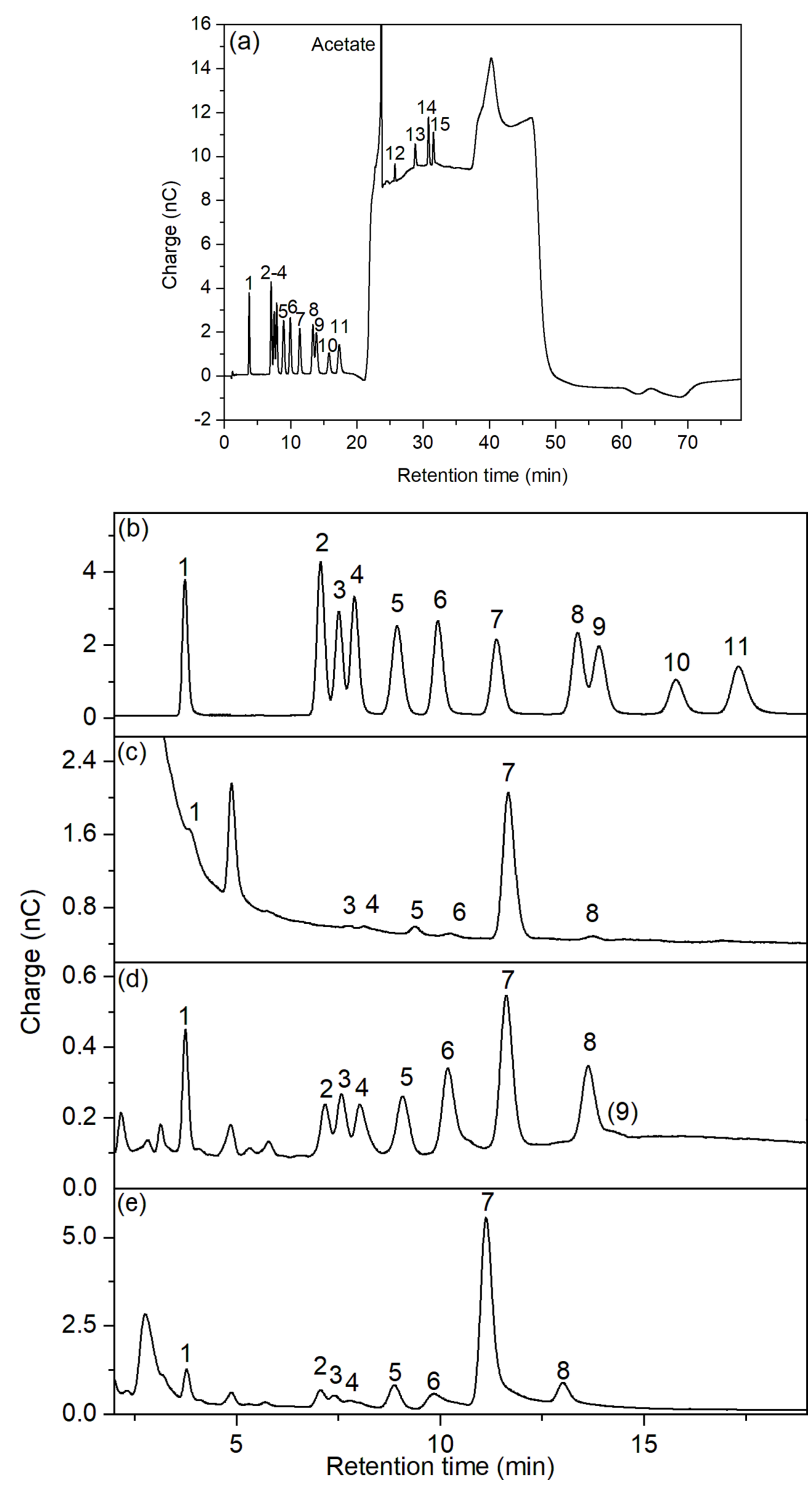

Figure 5. (a) Full chromatogram of standard solution $100 \mu \mathrm{gL}^{-1}$; (b-e) chromatograms of neutral sugars and amino sugars of (b) standard solution $100 \mu \mathrm{g} \mathrm{L}^{-1}$; (c) DFCHO in brine (B2) desalinated at natural $\mathrm{pH}$; (d) DCCHO in a seawater sample (SWS 3); (e) DCCHO in Arctic brine (B2). 1: fucose, 2: galactosamine, 3: rhamnose, 4: arabinose, 5: glucosamine, 6: galactose, 7: glucose, 8: xylose, 9: mannose, 10: fructose, 11: ribose, 12: muramic acid, 13: galacturonic acid, 14: glucuronic acid, 15: mannuronic acid.

ples during different field campaigns. SZ optimized the presented method and performed the chemical measurements. AE performed DCCHO analysis with supplied samples following her published protocol for evaluation purposes. All co-authors proofread and commented on the manuscript.

Competing interests. The authors declare that they have no conflict of interest.
Special issue statement. This article is part of the special issue "Marine organic matter: from biological production in the ocean to organic aerosol particles and marine clouds (ACP/OS inter-journal SI)". It is not associated with a conference.

Acknowledgements. We gratefully acknowledge the funding by the Deutsche Forschungsgemeinschaft (DFG, German Research Foundation). Additional support through the Leibniz Association SAW funding of the project "Marine biological production, organic aerosol particles and marine clouds: a Process Chain (MarParCloud)" is also gratefully acknowledged. We thank for the opportunities to use aqueous samples from various sampling campaigns in order to develop the method presented here. We thank Swantje Pöge for supporting work in the laboratory. We thank Jon Roa for DCCHO analysis following the Engel and Händel (2011) protocol. We thank Susanne Fuchs and Kristin Recklies, and Christian Weller of Thermo Fisher in his in-house collaborations for fruitful discussions. We thank Patrick Altmeier and Philip Kalkhoff from PCCell $\mathrm{GmbH}$ (Heusweiler, Germany) for guidance and technical support for helping to put ED in operation in our laboratory.

Financial support. This research has been supported by the Deutsche Forschungsgemeinschaft (DFG, German Research Foundation) - project ID 268020496 - TRR 172, within the Transregional Collaborative Research Center "ArctiC Amplification: Climate Relevant Atmospheric and SurfaCe Processes, and Feedback Mechanisms (AC) ${ }^{3}$ " in subproject B04. Additional support through the Leibniz Association SAW funding of the project "Marine biological production, organic aerosol particles and marine clouds: a Process Chain (MarParCloud)" (SAW-2016-TROPOS-2).

The publication of this article was funded by the Open Access Fund of the Leibniz Association.

Review statement. This paper was edited by Mario Hoppema and reviewed by two anonymous referees.

\section{References}

Barbaro, E., Kirchgeorg, T., Zangrando, R., Vecchiato, M., Piazza, R., Barbante, C., and Gambaro, A.: Sugars in Antarctic aerosol, Atmos. Environ., 118, 135-144, https://doi.org/10.1016/j.atmosenv.2015.07.047, 2015.

Benner, R. and Kaiser, K.: Abundance of amino sugars and peptidoglycan in marine particulate and dissolved organic matter, Limnol. Oceanogr., 48, 118-128, https://doi.org/10.4319/lo.2003.48.1.0118, 2003.

Berman-Frank, I., Rosenberg, G., Levitan, O., Haramaty, L., and Mari, X.: Coupling between autocatalytic cell death and transparent exopolymeric particle production in the marine cyanobacterium Trichodesmium, Environ. Microbiol., 9, 1415-1422, https://doi.org/10.1111/j.1462-2920.2007.01257.x, 2007.

Bianchi, T. S. and Canuel, E. A.: Chemical biomarkers in aquatic ecosystems, Princeton University Press, Princeton, NJ, 2011. 
Bichsel, Y. and von Gunten, U.: Formation of IodoTrihalomethanes during Disinfection and Oxidation of IodideContaining Waters, Environ. Sci. Technol., 34, 2784-2791, https://doi.org/10.1021/es9914590, 2000.

Bigg, E. K. and Leck, C.: The composition of fragments of bubbles bursting at the ocean surface, J. Geophys. Res., 113, D11209, https://doi.org/10.1029/2007JD009078, 2008.

Borch, N. H. and Kirchman, D. L.: Concentration and composition of dissolved combined neutral sugars (polysaccharides) in seawater determined by HPLC-PAD, Mar. Chem., 57, 85-95, https://doi.org/10.1016/S0304-4203(97)00002-9, 1997.

Borchard, C. and Engel, A.: Organic matter exudation by Emiliania huxleyi under simulated future ocean conditions, Biogeosciences, 9, 3405-3423, https://doi.org/10.5194/bg-9-34052012, 2012.

Borchard, C. and Engel, A.: Size-fractionated dissolved primary production and carbohydrate composition of the coccolithophore Emiliania huxleyi, Biogeosciences, 12, 1271-1284, https://doi.org/10.5194/bg-12-1271-2015, 2015.

Cisternas-Novoa, C., Le Moigne, F. A. C., and Engel, A.: Composition and vertical flux of particulate organic matter to the oxygen minimum zone of the central Baltic Sea: impact of a sporadic North Sea inflow, Biogeosciences, 16, 927-947, https://doi.org/10.5194/bg-16-927-2019, 2019.

Cowan, D. A.: Research in the problem of scaling of electrodialsis demineralizers, Texas Water Commission, Bulletin 6206, 29 pp., 1962.

Engbrodt, R.: Biogeochemistry of dissolved carbohydrates in the Arctic, Berichte zur Polar- und Meeresforschung (Reports on Polar and Marine Research), 396, 106 pp., 2001.

Engel, A. and Händel, N.: A novel protocol for determining the concentration and composition of sugars in particulate and in high molecular weight dissolved organic matter (HMW-DOM) in seawater, Mar. Chem., 127, 180-191, https://doi.org/10.1016/j.marchem.2011.09.004, 2011.

Engel, A., Bange, H. W., Cunliffe, M., Burrows, S. M., Friedrichs, G., Galgani, L., Herrmann, H., Hertkorn, N., Johnson, M., Liss, P. S., Quinn, P. K., Schartau, M., Soloviev, A., Stolle, C., Upstill-Goddard, R. C., van Pinxteren, M., and Zäncker, B.: The Ocean's Vital Skin: Toward an Integrated Understanding of the Sea Surface Microlayer, Front. Mar. Sci., 4, 165, https://doi.org/10.3389/fmars.2017.00165, 2017.

Ewert, M. and Deming, J. W.: Sea Ice Microorganisms: Environmental Constraints and Extracellular Responses, Biology, 2, 603-628, https://doi.org/10.3390/biology2020603, 2013.

Frossard, A. A., Russell, L. M., Burrows, S. M., Elliott, S. M., Bates, T. S., and Quinn, P. K.: Sources and composition of submicron organic mass in marine aerosol particles, J. Geophys. Res.-Atmos., 119, 12977-13003, https://doi.org/10.1002/2014JD021913, 2014.

Gain, E., Laborie, S., Viers, P., Rakib, M., Durand, G., and Hartmann, D.: Ammonium nitrate wastewater treatment by coupled membrane electrolysis and electrodialysis, J. Appl. Electrochem., 32, 969-975, 2002.

Galama, A. H., Saakes, M., Bruning, H., Rijnaarts, H. H. M., and Post, J. W.: Seawater predesalination with electrodialysis, Desalination, 342, 61-69, https://doi.org/10.1016/j.desal.2013.07.012, 2014.
Galier, S. and Balmann, H. R.: Demineralization of glucose solutions by electrodialysis: Influence of the ionic composition on the mass transfer and process performances, Can. J. Chem. Eng., 93, 378-385, https://doi.org/10.1002/cjce.22076, 2015.

Galier, S., Courtin, M., and Balmann, H. R.: Influence of the Ionic Composition on the Demineralisation of Saccharide Solutions by Electrodialysis, Procedia Engineer., 44, 826-829, https://doi.org/10.1016/j.proeng.2012.08.587, 2012.

Gao, Q., Nilsson, U., Ilag, L. L., and Leck, C.: Monosaccharide compositional analysis of marine polysaccharides by hydrophilic interaction liquid chromatography-tandem mass spectrometry, Anal. Bioanal. Chem., 399, 2517-2529, https://doi.org/10.1007/s00216-010-4638-z, 2011.

Gao, Q., Leck, C., Rauschenberg, C., and Matrai, P. A.: On the chemical dynamics of extracellular polysaccharides in the high Arctic surface microlayer, Ocean Sci., 8, 401-418, https://doi.org/10.5194/os-8-401-2012, 2012.

Han, L., Galier, S., and Roux-De Balmann, H.: Ion hydration number and electroosmosis during electrodialysis of mixed salt solution, Desalination, 373, 38-46, https://doi.org/10.1016/j.desal.2015.06.023, 2015.

Han, L., Galier, S., and Roux-De Balmann, H.: A phenomenological model to evaluate the performances of electrodialysis for the desalination of saline water containing organic solutes, Desalination, 422, 17-24, https://doi.org/10.1016/j.desal.2017.08.008, 2017.

Hawkins, L. N. and Russell, L. M.: Polysaccharides, Proteins, and Phytoplankton Fragments: Four Chemically Distinct Types of Marine Primary Organic Aerosol Classified by Single Particle Spectromicroscopy, Adv. Meteorol., 2010, 612132, https://doi.org/10.1155/2010/612132, 2010.

Hepp, J., Rabus, M., Anhäuser, T., Bromm, T., Laforsch, C., Sirocko, F., Glaser, B., and Zech, M.: A sugar biomarker proxy for assessing terrestrial versus aquatic sedimentary input, Org. Geochem., 98, 98-104, https://doi.org/10.1016/j.orggeochem.2016.05.012, 2016.

Iinuma, Y., Engling, G., Puxbaum, H., and Herrmann, H.: A highly resolved anion-exchange chromatographic method for determination of saccharidic tracers for biomass combustion and primary bio-particles in atmospheric aerosol, Atmos. Environ., 43, 13671371, https://doi.org/10.1016/j.atmosenv.2008.11.020, 2009.

Ittekkot, V., Brockmann, U., Michaelis, W., and Degens, E. T.: Dissolved free and combined carbohydrates during a phytoplankton bloom in the northern North Sea, Mar. Ecol. Prog. Ser., 4, 299305, 1981.

Josefsson, B. O.: Determination of soluble carbohydrates in sea water by partition chromatography after desalting by ionexchange membrane electrodialysis, Anal. Chim. Acta, 52, 6573, https://doi.org/10.1016/S0003-2670(01)80042-8, 1970.

Kaiser, K. and Benner, R.: Biochemical composition and size distribution of organic matter at the Pacific and Atlantic time-series stations, Mar. Chem., 113, 63-77, https://doi.org/10.1016/j.marchem.2008.12.004, 2009.

Kirchman, D. L., Meon, B., Ducklow, H. W., Carlson, C. A., Hansell, D. A., and Steward, G. F.: Glucose fluxes and concentrations of dissolved combined neutral sugars (polysaccharides) in the Ross Sea and Polar Front Zone, Antarctica, DeepSea Res. Pt. II, 48, 4179-4197, https://doi.org/10.1016/S09670645(01)00085-6, 2001. 
Kohn, R. and Kovác, P.: Dissociation constants of D-galacturonic and D-glucuronic acid and their O-methyl derivatives, Chem. zvesti, 32, 478-485, 1978.

Koprivnjak, J.-F., Pfromm, P. H., Ingall, E., Vetter, T. A., SchmittKopplin, P., Hertkorn, N., Frommberger, M., Knicker, H., and Perdue, E. M.: Chemical and spectroscopic characterization of marine dissolved organic matter isolated using coupled reverse osmosis-electrodialysis, Geochim. Cosmochim. Ac., 73, 42154231, https://doi.org/10.1016/j.gca.2009.04.010, 2009.

Krembs, C. and Deming, J. W.: The role of exopolymers in microbial adaptation to sea ice, in: Psychrophiles: from biodiversity to biotechnology, edited by: Margesin, R., Schinner, F., Marx, J. C., and Gerday, C., Springer, Berlin, Heidelberg, 247-264, 2008.

Krembs, C., Eicken, H., Junge, K., and Deming, J. W.: High concentrations of exopolymeric substances in Arctic winter sea ice: implications for the polar ocean carbon cycle and cryoprotection of diatoms, Deep-Sea Res. Pt. I. 49, 2163-2181, https://doi.org/10.1016/S0967-0637(02)00122-X, 2002.

Kuznetsova, M. and Lee, C.: Dissolved free and combined amino acids in nearshore seawater, sea surface microlayers and foams: Influence of extracellular hydrolysis, Aquat. Sci., 64, 252-268, 2002.

Leck, C., Gao, Q., Mashayekhy Rad, F., and Nilsson, U.: Size-resolved atmospheric particulate polysaccharides in the high summer Arctic, Atmos. Chem. Phys., 13, 12573-12588, https://doi.org/10.5194/acp-13-12573-2013, 2013.

Martí-Calatayud, M. C., García-Gabaldón, M., and Pérez-Herranz, V.: Mass Transfer Phenomena during Electrodialysis of Multivalent Ions: Chemical Equilibria and Overlimiting Currents, Appl. Sci., 8, 1566, https://doi.org/10.3390/app8091566, 2018.

Marty, J. C., Saliot, A., Buat-Ménard, P., Chesselet, R., and Hunter, K. A.: Relationship between the lipid compositions of marine aerosols, the sea surface microlayer, and subsurface water, J. Geophys. Res., 84, 5707-5716, https://doi.org/10.1029/JC084iC09p05707, 1979.

McCarthy, M., Hedges, J., and Benner, R.: Major biochemical composition of dissolved high molecular weight organic matter in seawater, Mar. Chem., 55, 281-297, https://doi.org/10.1016/S0304-4203(96)00041-2, 1996.

Meyer, A., Fischer, H., Kuzyakov, Y., and Fischer, K.: Improved RP-HPLC and anion-exchange chromatography methods for the determination of amino acids and carbohydrates in soil solutions, J. Plant Nutr. Soil Sc., 171, 917-926, https://doi.org/10.1002/jpln.200700235, 2008.

Mopper, K., Dawson, R., Liebezeit, G., and Ittekkot, V.: The monosaccharide spectra of natural waters, Mar. Chem., 10, 5566, https://doi.org/10.1016/0304-4203(80)90058-4, 1980.

Mopper, K., Schultz, C. A., Chevolot, L., Germain, C., Revuelta, R., and Dawson, R.: Determination of sugars in unconcentrated seawater and other natural waters by liquid chromatography and pulsed amperometric detection, Environ. Sci. Technol., 26, 133138, https://doi.org/10.1021/es00025a014, 1992.

Ohtaki, H. and Radnai, T.: Structure and dynamics of hydrated ions, Chem. Rev., 93, 1157-1204, https://doi.org/10.1021/cr00019a014, 1993.

Ottosen, L. M., Hansen, H. K., and Hansen, C. B.: Water splitting at ion-exchange membranes and potential differences in soil during electrodialytic soil remediation, J. Appl. Electrochem., 30, 11991207, https://doi.org/10.1023/A:1026557830268, 2000.
Pakulski, J. D. and Benner, R.: Abundance and distribution of carbohydrates in the ocean, Limnol. Oceanogr., 39, 930-940, 1994.

Panagiotopoulos, C. and Sempéré, R.: Analytical methods for the determination of sugars in marine samples: A historical perspective and future directions, Limnol. Oceanogr.-Meth., 3, 419-454, https://doi.org/10.4319/lom.2005.3.419, 2005.

Passow, U.: Transparent exopolymer particles (TEP) in aquatic environments, Prog. Oceanogr., 55, 287-333, https://doi.org/10.1016/S0079-6611(02)00138-6, 2002.

Rich, J. H., Ducklow, H. W., and Kirchman, D. L.: Concentrations and uptake of neutral monosaccharides along $14^{\circ} \mathrm{W}$ in the equatorial Pacific: Contribution of glucose to heterotrophic bacterial activity and the DOM flux, Limnol. Oceanogr., 41, 595-604, https://doi.org/10.4319/lo.1996.41.4.0595, 1996.

Rosenørn, T., Kiss, G., and Bilde, M.: Cloud droplet activation of saccharides and levoglucosan particles, Atmos. Environ., 40, 1794-1802, https://doi.org/10.1016/j.atmosenv.2005.11.024, 2006.

Russell, L. M., Hawkins, L. N., Frossard, A. A., Quinn, P. K., and Bates, T. S.: Carbohydrate-like composition of submicron atmospheric particles and their production from ocean bubble bursting, P. Natl. Acad. Sci. USA, 107, 6652-6657, https://doi.org/10.1073/pnas.0908905107, 2010.

Rutgers, A. J. and Hendrikx, Y.: Ionic hydration, T. Faraday Soc., 58, 2184-2191, https://doi.org/10.1039/tf9625802184, 1962.

Sadrzadeh, M. and Mohammadi, T.: Sea water desalination using electrodialysis, Desalination, 221, 440-447, 2008.

Sakugawa, H. and Handa, N.: Chemical studies on dissolved carbohydrates in the water samples collected from the North Pacific and Bering Sea, Oceanol. Acta, 8, 185-196, 1985.

Sata, T.: Ion Exchange Membranes: Preparation, Characterization, Modification and Application, Royal Society of Chemistry, Cambridge, 2004.

Singlande, E., Roux-de Balmann, H., Lefevbre, X., and Sperandio, M.: Improvement of the treatment of salted liquid waste by integrated electrodialysis upstream biological treatment, Desalination, 199, 64-66, https://doi.org/10.1016/j.desal.2006.03.020, 2006.

Sinnott, M.: Carbohydrate Chemistry and Biochemistry: Structure and Mechanism, Royal Society of Chemistry, Cambridge, 2007.

Skoog, A. and Benner, R.: Aldoses in various size fractions of marine organic matter: Implications for carbon cycling, Limnol. Oceanogr., 42, 1803-1813, https://doi.org/10.4319/lo.1997.42.8.1803, 1997.

Skoog, A., Biddanda, B., and Benner, R.: Bacterial utilization of dissolved glucose in the upper water column of the Gulf of Mexico, Limnol. Oceanogr., 44, 1625-1633, https://doi.org/10.4319/lo.1999.44.7.1625, 1999.

Thornton, D. C. O., Brooks, S. D., and Chen, J.: Protein and Carbohydrate Exopolymer Particles in the Sea Surface Microlayer (SML), Front. Mar. Sci., 3, 135-143, https://doi.org/10.3389/fmars.2016.00135, 2016.

Tsiakis, P. and Papageorgiou, L. G.: Optimal design of an electrodialysis brackish water desalination plant, Desalination, 173, 173-186, 2005.

Underwood, G. J. C., Aslam, S. N., Michel, C., Niemi, A., Norman, L., Meiners, K. M., Laybourn-Parry, J., Paterson, H., and Thomas, D. N.: Broad-scale predictability of carbohydrates and exopolymers in Antarctic and Arc- 
tic sea ice, P. Natl. Acad. Sci. USA, 110, 15734-15739, https://doi.org/10.1073/pnas.1302870110, 2013.

Vanoppen, M., Bakelants, A. F. A. M., Gaublomme, D., Schoutteten, K. V. K. M., Bussche, J. V., Vanhaecke, L., and Verliefde, A. R. D.: Properties Governing the Transport of Trace Organic Contaminants through Ion-Exchange Membranes, Environ. Sci. Technol., 49, 489-497, https://doi.org/10.1021/es504389q, 2015. van Pinxteren, M., Müller, C., Iinuma, Y., Stolle, C., and Herrmann, H.: Chemical Characterization of Dissolved Organic Compounds from Coastal Sea Surface Microlayers (Baltic Sea, Germany), Environ. Sci. Technol., 46, 10455-10462, https://doi.org/10.1021/es204492b, 2012.

Vetter, T. A., Perdue, E. M., Ingall, E., Koprivnjak, J.-F., and Pfromm, P. H.: Combining reverse osmosis and electrodialysis for more complete recovery of dissolved organic matter from seawater, Sep. Purif. Technol., 56, 383-387, https://doi.org/10.1016/j.seppur.2007.04.012, 2007.

Wakeham, S. G., Lee, C., Hedges, J. I., Hernes, P. J., and Peterson, M. J.: Molecular indicators of diagenetic status in marine organic matter, Geochim. Cosmochim. Ac., 61, 5363-5369, https://doi.org/10.1016/S0016-7037(97)00312-8, 1997.

Walker, W. S., Kim, Y., and Lawler, D. F.: Treatment of model inland brackish groundwater reverse osmosis concentrate with electrodialysis - Part II: Sensitivity to voltage application and membranes, Desalination, 345, 128-135, https://doi.org/10.1016/j.desal.2014.04.026, 2014.

Wendisch, M., Macke, A., Ehrlich, A., Lüpkes, C., Mech, M., Chechin, D., Dethloff, K., Velasco, C. B., Bozem, H., Brückner, M., Clemen, H.-C., Crewell, S., Donth, T., Dupuy, R., Ebell, K., Egerer, U., Engelmann, R., Engler, C., Eppers, O., Gehrmann, M., Gong, X., Gottschalk, M., Gourbeyre, C., Griesche, H., Hartmann, J., Hartmann, M., Heinold, B., Herber, A., Herrmann, H., Heygster, G., Hoor, P., Jafariserajehlou, S., Jäkel, E., Järvinen, E., Jourdan, O., Kästner, U., Kecorius, S., Knudsen, E. M., Köllner, F., Kretzschmar, J., Lelli, L., Leroy, D., Maturilli, M., Mei, L., Mertes, S., Mioche, G., Neuber, R., Nicolaus, M., Nomokonova, T., Notholt, J., Palm, M., van Pinxteren, M., Quaas, J., Richter, P., Ruiz-Donoso, E., Schäfer, M., Schmieder, K., Schnaiter, M., Schneider, J., Schwarzenböck, A., Seifert, P., Shupe, M. D., Siebert, H., Spreen, G., Stapf, J., Stratmann, F., Vogl, T., Welti, A., Wex, H., Wiedensohler, A., Zanatta, M., and Zeppenfeld, S.: The Arctic Cloud Puzzle: Using ACLOUD/PASCAL Multiplatform Observations to Unravel the Role of Clouds and Aerosol Particles in Arctic Amplification, B. Am. Meteorol. Soc., 100, 841-871, https://doi.org/10.1175/BAMS-D-18-0072.1, 2019.
Wirth, M. A., Sievers, M., Habedank, F., Kragl, U., SchulzBull, D. E., and Kanwischer, M.: Electrodialysis as a sample processing tool for bulk organic matter and target pollutant analysis of seawater, Mar. Chem., 217, 103719, https://doi.org/10.1016/j.marchem.2019.103719, 2019.

Wisniewski, C., Persin, F., Cherif, T., Sandeaux, R., Grasmick, A., and Gavach, C.: Denitrification of drinking water by the association of an electrodialysis process and a membrane bioreactor: feasibility and application, Desalination, 139, 199-205, 2001.

Zeppenfeld, S., van Pinxteren, M., Hartmann, M., Bracher, A., Stratmann, F., and Herrmann, H.: Glucose as a Potential Chemical Marker for Ice Nucleating Activity in Arctic Seawater and Melt Pond Samples, Environ. Sci. Technol., 53, 8747-8756, https://doi.org/10.1021/acs.est.9b01469, 2019.

Zeppenfeld, S., van Pinxteren, M., and Herrmann, H.: Free neutral monosaccharides and combined monosaccharides in seawater and related saline matrices, PANGAEA, https://doi.org/10.1594/PANGAEA.910575, 2020. 